\title{
A Rare Case of Vallecular Cyst Causing Neonatal Stridor
}

\author{
Worood Husain*, Jalal Almarzooq, Deena Shabib \\ Department of ENT, Head and Neck Surgery, Salmaniya Medical Complex, Manama, Kingdom of Bahrain \\ Email: *drworood@hotmail.com
}

How to cite this paper: Husain, W., Almarzooq, J. and Shabib, D. (2018) A Rare Case of Vallecular Cyst Causing Neonatal Stridor. International Journal of Otolaryngology and Head \& Neck Surgery, 7, 313316.

https://doi.org/10.4236/ijohns.2018.76031

Received: September 12, 2018

Accepted: November 6, 2018

Published: November 9, 2018

Copyright $\odot 2018$ by authors and Scientific Research Publishing Inc. This work is licensed under the Creative Commons Attribution International License (CC BY 4.0).

http://creativecommons.org/licenses/by/4.0/

\begin{abstract}
Vallecular cyst is uncommon laryngeal lesion and generally asymptomatic. However, when large in size or occur in a small airway like in neonates, it causes respiratory and feeding difficulties. Here we report a rare case of symptomatic vallecular cyst in a neonate.
\end{abstract}

\section{Keywords}

Vallecular Cyst, Neonatal Stridor, Cyst at Base of Tongue

\section{Introduction}

Vallecular cyst is uncommon laryngeal lesion and generally asymptomatic. However, presenting in neonates may cause respiratory and feeding difficulties which can lead to significant morbidity and mortality [1]. Symptoms might mimic more common and benign lesions in neonate (e.g. laryngomalacia), hence it is important to refer patients with neonatal stridor to an otolaryngologist for proper assessment and treatment [2] [3]. Here we report a rare case of symptomatic vallecular cyst in a neonate.

\section{Case Report}

A one month old boy was admitted under pediatric care in our hospital with noisy breathing and progressive respiratory distress that precipitated by crying with interrupted feeds. The baby was a full term boy delivered through normal vaginal delivery with uneventful immediate postnatal period. He had no dysmorphic features and was stable vitally with occasional inspiratory stridor on crying with suprasternal and subcostal recessions, without cyanosis. Flexible nasopharyngoscopy showed an omega shaped elongated epiglottis that was pushed posteriorly against the posterior pharyngeal wall by a cystic mass occupying the 
area between the base of tongue and vallecula. CT scan was arranged but patient breathing started to deteriorate, and it was decided by pediatric intensivist and airway team in the hospital to undergo urgent examination under general anesthesia and direct laryngoscopy with a possibility of tracheostomy if intubation failed. Intubation was challenging as the airway was obscured by the cyst, but was successfully done by an experienced pediatric anesthetist with the assistance of videolaryngoscopy. Rigid direct laryngoscopy showed a clear fluid containing cyst arising from the left vallecula (Figure 1). It was excised completely endoscopically by cold instruments. Histopathology showed squamous epithelial lining without thyroid tissue, compatible with vallecular cyst (Figure 2). Follow-up of the patient showed no more stridor or respiratory distress, and no recurrence of the cyst.

\section{Discussion}

Vallecular cyst is uncommon laryngeal lesion that accounts only for $10.5 \%$ [4] of all laryngeal cysts and generally asymptomatic [1] [3] [4] [5]. However, presentation depends largely on the size and the age of presentation [3]. In infancy, it causes stridor, respiratory distress, feeding problems and failure to thrive [1] [2]

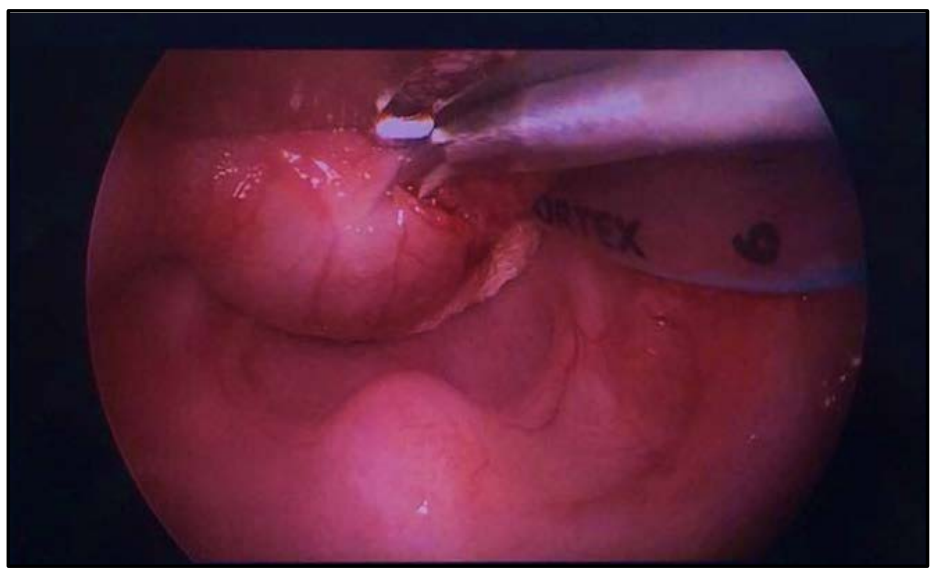

Figure 1. Intraoperative endoscopic view of the cyst.

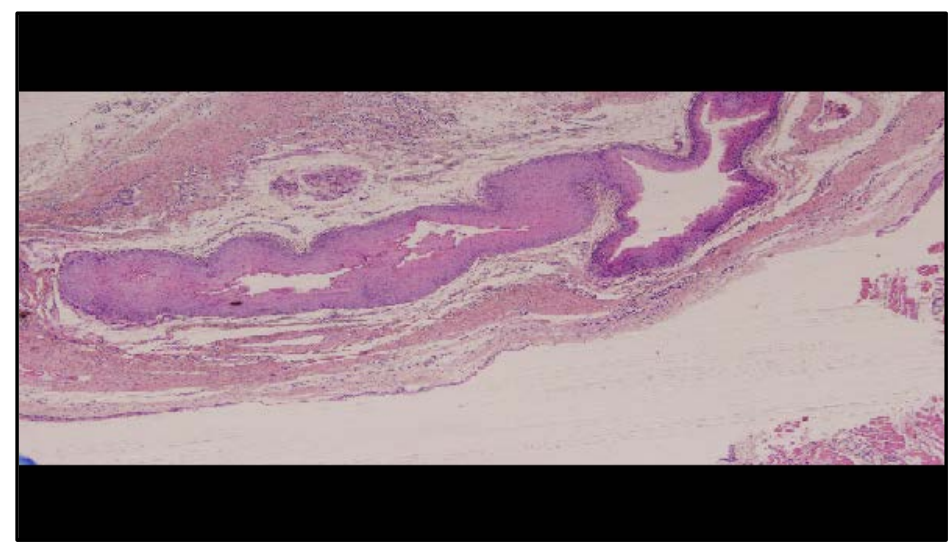

Figure 2. Histopathological slide of squamous cell lined cyst. 
[3] [6] [7] [8]. These symptoms require great attention by the attending physician as missing such cases can lead to disastrous consequences [1] [5] [9]. There are two pathological hypotheses for the development of theses lesions in neonates, either ductal blockage of mucous glands or embryological defect of their lymphatic drainage [2] [3] [6] [7] [8]. Flexible nasopharyngoscopy is the most important investigation in neonatal stridor as it can demonstrate theses lesions [2] [3]. Imaging like CT and MRI prior to surgical treatment is of paramount importance and shows the extent of the lesion, vascularity and differentiates it from more common laryngeal lesions in this age group [2] [7] [8]. Unfortunately this was not done in our case as patient condition deteriorated quickly. Direct laryngoscopy with marsupialization or excision of the cyst is the treatment of choice [2] [3] [6] [7] [8]. Repeated aspiration is proved to be simple treatment but with a possibility of recurrence [8]. Theses cysts tend to associate with laryngomalcia [3] [4] [7] [8] [10] that might need to be treated surgically in the same setting if it was severe [10].

\section{Conclusion}

Vallecular cyst is rare cause of neonatal stridor that can lead to rapid deterioration of breathing in this age group; hence it is important not to make the assumption of more common and benign causes of stridor in neonates like laryngoomalcia without referring the patient to an otolaryngologist for airway assessment by flexible nasopharyngoscopy.

\section{Conflicts of Interest}

The authors declare no conflicts of interest regarding the publication of this paper.

\section{References}

[1] Gaxa, L., Hlatshwayo, B.E. and Modishi, M.H. (2015) Vallecular Cyst. Case Reports International, 4, 6-10.

[2] Torer, B., Cetinkaya, B., Yilmaz, S., Yimazer, C. and Glucan, H. (2015) Upper Airway Obstruction in a Newborn with Vallecular Cyst. Journal of Neonatal Surgery, 4 , 45 .

[3] Mulchay, C.F., Reddy, S.K., Wikner, E.E. and Mudd, P.A. (2017) Neonatal Airway Anomaly: Vallecular Cyst. BMJ Case Reports.

https://doi.org/10.1136/bcr-2017-223082

[4] Lin, Y.H. and Lin, M.Y. (2018) An Undulating Vallecular Cyst. Ears Nose Throat Journal, 50, 109-110.

[5] Gogia, S., Agarwal, S.K. and Agarwal, A. (2014) Vallecular Cysts in Neonates: Case Series-A Clincosurgical Insight. Case Reports in Otolaryngology, 764-860.

[6] Cheng, S.S., Forte, V. and Shah, V.S. (2009) Symptomatic Congenital Valeecular Cyst in a Neonate. The Journal of Pediatrics, 155, 446. https://doi.org/10.1016/j.jpeds.2009.01.076

[7] Mallick, S.A., Qureshi, T.N., Varghese, A.M. and Busaidi, M.M.A. (2017) Congenital Vallecular Cyst: A Rare and Potentially Lethal Condition. Journal of College of 
Physicians and Surgeons Pakistan, 27, 376-377.

[8] Coban, K., Bas, C. and Aydin, E. (2018) Vallecular Cyst in a 1 Month Old Infant. Journal of Otolaryngology Research, 1, 105.

[9] Yao, T.C., Chiu, C.Y., Wu, L.J. and Huang, J.L. (2004) Failure to Thrive Caused by the Coexistence of Vallecular Cyst, Laryngomalacia and Gastroesophageal Reflux in an Infant. International Journal of Pediatric Otolaryngology, 68, 1459-1464.

[10] Gandhi, S., Raza, S.A., Thekedar, P. and Moshra, P. (2011) Congenital Vallecular Cyst with Laryngomalacia: A Report of Two Cases. Journal of Laryngology \& Voice, 1, 27-29. https://doi.org/10.4103/2230-9748.76134 